\title{
Relatos y metáforas. Dos aproximaciones para comprender los procesos de tesis ${ }^{1}$
}

\author{
Ana Maria Bartolini ${ }^{2}$ \\ UADER, Paraná, Argentina; \\ UNER, Entre Ríos, Argentina \\ lastresana@arnet.com.ar \\ Daniela Roxana Vivas ${ }^{3}$ \\ UADER, Paraná, Argentina \\ danielarvivas@hotmail.com \\ Carmela Ferreira ${ }^{4}$ \\ UADER, Paraná, Argentina \\ carmelaferreira@yahoo.com.ar \\ Natalia Petric ${ }^{5}$ \\ UADER, Paraná, Argentina \\ nataliapetric@hotmail.com \\ Recibido: 12 de enero de 2016 \\ Aceptado: 13 de junio de 2016 \\ Disponible en línea: 20 de diciembre de 2016
}

\section{Relatos y metáforas. Dos aproximaciones para comprender los procesos de tesis}

\footnotetext{
Artículo de investigación, sin financiamiento institucional. Las autoras se desempeñan como asesoras, tutoras y evaluadoras de proyectos y de tesis.

2 Especialista y Magister Scientiae en Metodología de la Investigación Científica y Técnica, Universidad Nacional de Entre Ríos (UNER) (Argentina). Doctora en Educación, Universidad de San Andrés (Argentina). Profesora, Universidad Autónoma de Entre Ríos (UADER) y docente, Facultad de Ciencias de la Educación, UNER (Paraná y Entre Ríos, Argentina).

3 Licenciada en Matemática Aplicada y Especialista en Didácticas Específicas, Universidad Nacional del Litoral (Argentina). Docente de las cátedras Matemática y Estadística, UADER (Paraná, Argentina).

4 Técnica en Psicogerontología, y tesista de la Licenciatura en Psicología, UADER (Argentina). Interina en Metodología de la Investigación, UADER (Paraná, Argentina).

5 Licenciada en Psicopedagogía. Doctoranda en Psicopedagogía, Universidad Católica Argentina (Argentina). Integrante del Departamento de Pedagogía, UADER (Paraná, Argentina).
} 


\title{
Resumen
}

Se presenta un análisis complementario de dos fuentes de información: entrevistas focalizadas y selección de objetos - pintura, imagen, palabra, frase, foto, etc.-. Ambas técnicas pretendieron comprender, desde una perspectiva cualitativa, el proceso de tesis de egresados de dos facultades de la Universidad Autónoma de Entre Ríos (UADER). A partir de las entrevistas, se construyeron trayectorias grupales de tesis, en tanto que los objetos elegidos fueron interpretados como metáforas de los procesos. Dichas fuentes discursivas y metafóricas se convierten en dos caminos diferentes, pero complementarios, cuya confluencia enriquece y completa la comprensión. Los hallazgos presentados dan cuenta de: una mayor variabilidad comprensiva por parte del análisis de metáforas; el otorgamiento de un plus de sentido de las metáforas sobre el relato de la experiencia; la validación de los hallazgos generales en función de ambas fuentes; y la profundización en la comprensión de procesos complejos, como es la realización de una tesis.

Palabras clave: relatos; metáforas; proceso de tesis; nivel de grado

\section{Discourse and Metaphors. Two approaches to Understanding the Thesis Process}

\begin{abstract}
This article presents a complementary analysis from two sources: focused interviews and selection of objects (painting, image, word, phrase, picture, etc.). Both techniques sought to understand, from a qualitative perspective, the graduates' thesis process of two faculties of Universidad Autónoma de Entre Ríos (UADER). Thesis group journeys were constructed from interviews and selected objects were interpreted as metaphors of such processes. The confluence of these two different, but complementary, discursive and metaphorical sources enriches and completes comprehension. The findings show a greater comprehensive variability in metaphorical analysis; metaphors provide more meaning when narrating experience, and the validation of findings based on the two sources. They also allow a deeper understanding of complex processes, such as the completion of a thesis.
\end{abstract}

Keywords: discourses; metaphors; thesis process; undergraduate

\section{Relatos e metáforas. Duas abordagens para a compreensão dos processos de tese}

\section{Resumo}

Apresenta-se análise complementar das duas fontes de informação: entrevistas focalizadas e seleção de objetos (pintura, imagem, palavra, frase, foto, etc.). Ambas as técnicas procuraram compreender, a partir de uma perspectiva qualitativa, o processo de tese de graduados de duas faculdades da Universidade Autônoma de Entre Rios (UADER). A partir das entrevistas foram construídas trajetórias grupais de tese, enquanto os objetos escolhidos foram interpretados como metáforas do processo. Estas fontes discursivas e metafóricas tornam-se duas formas diferentes, mas complementares, cuja confluência enriquece e completa a compreensão. Os achados apresentados dão conta de: maior variabilidade no entendimento por parte da analise de metáforas; outorgamento de um aditamento de sentido das metáforas sobre o relato da experiência; validação dos achados gerais de acordo com ambas as fontes; e o aprofundamento na compreensão de processos complexos, tais como a elaboração de uma tese.

Palavras-chave: relatos; metáforas; processo de tese; nível de grau 


\section{Introducción}

La investigación base de este artículo se inscribe en una línea de estudios que busca comprender los complejos procesos de tesis en el nivel universitario de grado ${ }^{6}$. Dicha complejidad proviene de la multiplicidad de dimensiones que los atraviesan, entre ellas se señalan las individuales y las institucionales que, combinadas entre sí, obran de distintas maneras. A la vez, existen protagonistas y momentos que operan de modo diferente, de suerte que la trayectoria de cada tesista se construye a partir de la peculiar interacción de estos componentes. Esta complejidad habilita, así, una diversidad de miradas que permiten desarrollar una mayor comprensión acerca del fenómeno.

Son escasas las investigaciones argentinas sobre los procesos de tesis en el nivel universitario de grado, en comparación con las de posgrado que fueron realizadas por Carlino (2003, 2004, 2008, 2009), o Narvaja de Arnoux, Borsinger, Carlino, Di Stéfano, Pereira y Silvestre (2004), entre otras. En general, en varios países solo las carreras de posgrado tienen el requisito de realizar una tesis para egresar.

Este artículo se propone comprender los procesos de tesis experimentados por egresados de carreras de grado de la Universidad Autónoma de Entre Ríos (UADER) ${ }^{7}$, desde dos fuentes de información diversas. La primera de ellas es la narración de las trayectorias de tesis por parte de los graduados; la segunda, los objetos elegidos por ellos - palabras, fotos, pinturas, imágenes-, que permitieron simbolizar y significar la experiencia como metáfora de los procesos vividos. Dichas fuentes se convierten en dos caminos diferentes pero complementarios, cuya confluencia enriquece y completa la comprensión. Un diseño cualitativo y una perspectiva microsocial recuperan las voces de los tesistas, a la vez que posibilitan la identificación de los factores que es necesario promover, así como de aquellos que es preciso evitar.

6 En la República Argentina el nivel de grado incluye los profesorados y las licenciaturas universitarias. En Estados Unidos y algunos países latinoamericanos, entre otros, este se corresponde con el nivel de pregrado.

7 Este artículo profundiza los hallazgos de la investigación institucional titulada "La trayectoria de los tesistas. Un estudio en egresados de la UADER" integrada por Bartolini, Vivas, Ferreira y Petric. La muestra se conformó con egresados de las facultades de Humanidades, Artes y Ciencias Sociales, y Ciencias de la Gestión de dicha Universidad. En 2013 la UADER aprobó el Informe Final. 
La investigación cualitativa se caracteriza por ser, en palabras de Denzin y Lincoln (2011), multimetódica, naturalista e interpretativa; esto implica comprender los fenómenos en términos del significado que las personas les otorgan. Entre tanto, Vasilachis de Gialdino (2006, pp. 24-25) expresa que dicha investigación:

Abarca el estudio, uso y recolección de una variedad de materiales empíricos - estudio de casos, experiencia personal, introspectiva, historia de vida, entrevista, textos observacionales, históricos, interaccionales y visuales- que describen los momentos habituales y problemáticos y los significados en la vida de los individuos.

El carácter multimetódico habilita el uso de diversas técnicas de recolección, o aun mejor, de producción de información, para así favorecer una interpretación ajustada al fenómeno estudiado.

Por su parte, Scribano (2008) expresa que la investigación cualitativa "rompe y construye caminos renovados para ver -el mundo-con otros y los otros que participan en la investigación" (p. 254). Es asî que "desde la antropología visual a la sociología visual, desde la etnomusicología a los estudios de cultura popular, se ha intentado captar lo que los sujetos desean expresar 'más acá' de la sola narración verbal" (Scribano, 2013, p. 83). Además, el "avance de las estrategias de investigación social -al incorporar progresiva y sostenidamente a las 'tecnologías de captación de la expresividad'- ha podido acercar la brecha entre lo que el investigador ve y aquello que el sujeto expresa" (Scribano, 2013, p. 83).

La posibilidad de incorporar y construir varias técnicas de investigación, se refleja en una pluralidad de estudios, entre los que se destacan los encuentros creativos expresivos (Scribano, 2013), la fotoelucidación (Harper, 2002; Meo y Dabenigno, 2011; Bonetto, 2014; Schwarz, 2014), los métodos visuales (Banks, 2010), los dibujos de niños (Tay-Lim and Lim, 2013), y los retratos de collages (Gerstenblatt, 2013). 
La inclusión de imágenes, films, videos, fotografias, diagramas, dibujos, etc., comenzó a utilizarse como medio para explorar fenómenos sociales, desde hace aproximadamente 30 años, en el contexto anglosajón, en general, y en Estados Unidos, en particular. En el mundo hispanohablante, específicamente en Argentina, se observa una tibia emergencia de estudios que usan materiales visuales entre sus estrategias metodológicas (Meo y Dabenigno, 2011, p. 15). Recursos tales como la fotografia, la danza, la música y la creación artística han permitido la generación de diferentes dispositivos de producción y análisis de datos cualitativos, que posibilitan una mayor comprensión de los fenómenos sociales.

En consecuencia, la apertura de caminos, a través de modos no convencionales de exploración científica, propicia el encuentro y la integración de perspectivas entre los protagonistas y el investigador alrededor de un "trozo" de vida de los primeros (Scribano, 2008).

Entonces, si bien la investigación cualitativa se caracteriza principalmente por su diseño flexible (Mendizábal, 2006), existe una hegemonía de los datos verbales en los modos de producir y presentar resultados (Meo y Dabenigno, 2011). En este sentido, este estudio incluyó el uso de metáforas como estrategia que permite generar pensamiento creativo, que, junto al crítico, es esencial en la investigación cualitativa (Patton citado por Strauss y Corbin, 2002).

La palabra 'metáfora' proviene del concepto latino metaphora y este, a su vez, de un vocablo griego que en español se interpreta como 'traslación'. Se trata de la aplicación de un concepto o de una expresión sobre una idea o un objeto al cual no describe de manera directa, con la intención de sugerir una comparación con otro elemento y facilitar su comprensión.

Si bien las metáforas han sido mayormente asimiladas al recurso poético, en su definición central aluden a la posibilidad de conectar dos aspectos disímiles en algo nuevo que impide invisibilizar las diferencias entre ambos. 
De Gracia y Casteló (2003) describen un debate acerca del uso de las metáforas en ciencias, y expresan que aquellas pueden entenderse como "una figura del habla que establece una comparación implícita entre dos entidades desiguales, y que implica un salto cualitativo entre los objetos considerados que va desde la mera comparación hasta una cierta forma de identificación, para dar lugar a una nueva entidad que comparte las características de ambos" (pp. 30-31).

Durante bastante tiempo se consideró que las expresiones metafóricas desempeñaban un papel secundario en la ciencia, ya que lo característico del lenguaje científico era la precisión y la ausencia de ambigüedad. En contraste, Ortega y Gasset (citado por De Gracia y Casteló, 2003) reivindica el uso de la metáfora en la ciencia, asignándole un papel primordial en la caracterización del pensamiento científico. Dicho autor distinguía dos usos de la metáfora: el primero, de carácter superficial, es aquel en el que la metáfora se reduce a una simple transposición de nombres; es decir, tiene un uso traslaticio y su empleo es propio de la literatura, especialmente de la poesía. El otro y más profundo sentido remite a la complejidad de definir ciertos objetos, por lo que prefiere el apoyo en objetos fáciles y asequibles para pensar lo multidimensional.

Lakoff y Johnson (2001) han estudiado la naturaleza de los sistemas conceptuales humanos, en temas como el tiempo, la causalidad, las emociones, la moral, la política, entre otros, a través de su teoría sobre el pensamiento metafórico. La idea central es que la metáfora, más allá de ser un aspecto formal del lenguaje, posibilita estructurar conceptos a partir de otros.

Gran parte de los conceptos se estructurarian de esta forma. Además, las metáforas que el ser humano usa para construir su sistema conceptual poseen una sistematicidad interna -a través de las relaciones entre sí-, y determinan la forma en que se percibe y actúa sobre el mundo. Estos autores expresan que la metáfora "impregna la vida cotidiana, no solamente el lenguaje, sino también el pensamiento y la acción" (p. 39). Con énfasis expresan que "nuestro sistema conceptual ordinario, en términos del cuál pensamos y actuamos, 
es fundamentalmente de naturaleza metafórica" (p. 39). Cabe anotar que la metáfora también es propuesta como un modo de pensar en la infancia y un recurso para el desarrollo de la creatividad (Civarolo, Aiello y Pérez, 2013).

La apelación a las metáforas contribuye a la doble hermenéutica propia de la investigación social, esto es, a una interpretación más ajustada de los procesos sociales. Ellas son utilizadas en todo dominio de conocimiento, dado que son nuestros principales instrumentos para integrar diversos fenómenos y puntos de vista sin destruir sus diferencias (Brown citado por Scribano, 2013).

En consonancia con lo anteriormente expuesto, la propuesta del artículo es complejizar, complementar y profundizar las experiencias de procesos de tesis, desde la voz de los sujetos implicados, apelando tanto a la palabra como medio de expresión que evoca la linealidad del lenguaje, como también a la perspectiva holística que propone la elección de metáforas que posibilitan el ensamble del conocimiento y del afecto (Lubar y Getz citados por Styles y Radloff, 2000).

En relación con las técnicas de recolección y con el análisis de los datos, un primer momento analítico se basó en varias lecturas del relato de cada egresado, proveniente de las entrevistas focalizadas. Esto permitió caracterizar inicialmente cada una de las experiencias de tesis. Las categorias resultantes de esta primera lectura, consistieron en una descripción general y comparada de las experiencias y de los factores facilitadores y obstaculizadores, asociados con los procesos de tesis según las voces de los egresados.

Este primer análisis ayudó a identificar tópicos recurrentes - director, materias metodológicas, sentimientos, motivación, entre otrosy momentos del proceso -inicio, desarrollo y cierre-, lo que derivó en una indagación más profunda de la pregunta inicial. A su vez posibilitó el refinamiento de las categorías formuladas inicialmente.

Un segundo momento analítico permitió pasar de un sistema de categorías descriptivo a otro selectivo y teórico, en el cual se logró la 
emergencia de regularidades y diferencias en los relatos. Además, permitió agrupar las trayectorias, que son individuales, y especificar cuatro tipos de trayectos diferentes por los que atravesaron los procesos de tesis de los egresados.

Los 26 objetos aportados en las entrevistas, considerados metáforas de los procesos de tesis, se analizaron según los criterios de formato, densidad y temas.

Finalmente, se identificaron las continuidades y discontinuidades sobre los procesos de tesis desde las fuentes discursivas y metafóricas utilizadas.

Este artículo desarrolla, en primer lugar, la descripción de las trayectorias grupales (Bartolini, Vivas, Ferreira y Petric, 2013), construidas a partir de los relatos de los egresados participantes de la investigación. En segundo lugar, se presenta la interpretación de las metáforas aportadas por los egresados. Finalmente, se ofrecen los hallazgos y reflexiones provenientes de la convergencia y complementariedad de los datos provistos por ambas técnicas.

\section{Relatos: del recorrido individual a las trayectorias grupales de tesis}

Se entiende por trayectoria grupal el recorrido de los tesistas desde el inicio del proceso de tesis hasta el momento en el que se considera que finalizó. En los relatos de los entrevistados aparecieron hallazgos vinculados con las dimensiones -individual, curricular, institucional-, los momentos -inicio, desarrollo y cierre-y los protagonistas -directores, pares, etc.- y aunque cada uno de los 31 entrevistados vivió su proceso de tesis de manera particular, se logró la construcción de cuatro trayectorias grupales que permiten ubicarlos en alguna de ellas. 
Se buscó que cada trayectoria grupal fuera denominada según su esencia, así: la tesis, una formalidad; el proceso de tesis con una mirada de crecimiento; lo logró, pero lo sufrió; sobrevolando la tesis. A continuación, dichas trayectorias son descritas brevemente.

\section{La tesis, una formalidad}

En esta trayectoria grupal fueron incluidos tres egresados que relataron su proceso de manera "desencarnada" o con escasas referencias al plano afectivo de la experiencia, no informando suficientemente como para reconocer sentimientos, involucramientos, procesos internos o marcas subjetivas profundas.

Para Carlos, la tesis formaba parte de un proyecto académico mayor que incluía la realización de un doctorado en el exterior. Él mismo se explayó sobradamente sobre el contenido de la tesis, los referentes teóricos del área disciplinar, las fuentes internacionales consultadas y los modos de abordarla. Al respecto, expresó:

Lo que es el tema principal de la tesis lo decidió el director de tesis, que aparte de ser mi director era tío, un tío por el cual decido yo ser licenciado en economía. Él está en París, tiene un doctorado allá en Economía. Cuando venía, siempre hablaba de economía y desde ahí me empezó a gustar. Entonces, él fue el que me ayudó durante la carrera y sobre todo para hacer la tesis, la tesina, y elegir el tema [...]. Y también el hecho de meterle pata, por así decirlo, a la tesina, era porque mi proyecto era hacer un doctorado allá en Francia. Era terminar eso, hacer una maestría en Buenos Aires, la cual comencé, terminé el cursado y no la pude terminar porque mi mujer quedó embarazada y me vine a establecer acá a Paraná.

Otro egresado, en un relato breve, destacó el rol de su director, la formación recibida durante la carrera y la colaboración de las personas que entrevistó. La otra egresada, por su parte, hizo una constante mención a la directora, pero sin informar las características de la relación mantenida. 


\section{El proceso de tesis con una mirada de crecimiento}

En esta trayectoria grupal se incluyó a 16 de los 31 egresados, quienes relataron su proceso de modo positivo o como una experiencia que en general fue satisfactoria, y en la que aparecieron numerosos aprendizajes y tuvieron una gestión adecuada del tiempo; los 31 percibieron el proceso como un logro.

Así mismo, sobresalieron las características y los recursos individuales aportados por los tesistas para transformar los déficits y las carencias institucionales, en oportunidades de avance y aprendizaje. Aquí se advirtió claramente la relación inversamente proporcional entre condiciones esperables y recursos y estrategias subjetivas puestas en juego por los tesistas. En otros términos, ante la escasez de directores, de regulaciones, de encuentros entre pares, de referentes institucionales y disciplinares, de talleres de escritura, de materias metodológicas, etc., que proveyesen de los necesarios reaseguros para el avance del proceso, los tesistas diseñaron e implementaron sus propios recursos y estrategias subjetivas.

Aquí destacaron los aspectos positivos sobre las dificultades y limitaciones mencionadas. Las categorias "darse cuenta" y "hacerse cargo" de los procesos de tesis aparecieron reflejadas en mayor medida en los egresados de esta trayectoria grupal en comparación con los de las otras tres.

Por otro lado, los egresados no percibieron como prolongado -aunque lo fue- el tiempo requerido por la tesis, y lo vivieron como la ineludible coordenada en la que los procesos históricos -las tesis- se tejen.

A su vez, los egresados no sintieron la tesis como una mera exigencia académica ni la vivieron como "obligatoria", por el contrario, crearon momentos para pensar, para leer, para escribir, y para intercambiar ideas de maneras diversas y efectivas. En este sentido, Muriel relató:

Entrevistadora: Hay momentos en que uno deja, que no tiene ganas y necesita como un empujoncito. 
Muriel: No, era cuestión de tener tiempo y sentarse. Mientras yo veía que tenía tiempo un fin de semana o una tarde, mientras no estaba cansada me sentaba a hacerlo, porque era el momento mío, de algo que a mí me gustaba en realidad, era cuestión de tener tiempo.

Además, estos entrevistados reconocieron que la soledad era inherente al trabajo individual que la tesis supone y expresaron haber vivido verdaderos insights -o aprendizajes-del oficio de investigador social.

Resultó muy significativa la alusión a que la tesis tuvo dos dimensiones: una teórica y otra subjetiva, y que en varios casos se integraron, permitiendo disfrutar del proceso. De otro lado, existió percepción del plano de la interioridad, es decir, los relatos de estos egresados contenian expresiones que mostraron contacto con sus afectos, con sus emociones, con el dolor, con el deseo como brújula que moviliza, y con distintos grados de disfrute y de aprendizaje, a diferencia de otras trayectorias grupales. Vinculado con esto, Arahí comentó:

Bueno, yo creo que fue un proceso de decisión interno, mío, de decir me recibo o me recibo [...] me fui también impulsando, pero fue un trabajo de mucho esfuerzo, como yo siempre digo, y les decía a mis compañeros a quienes estuve ayudando en su momento, hay que libidinizar la tesis, hay que ponerle tu deseo, tu libido, tu energía; todo tenés que ponérselo a la tesis para poder sacarla adelante.

El proceso de tesis fue asociado también al rito de pasaje, a la transformación que significó la tesis como último tramo de la formación profesional, como vía de acceso al rol profesional.

Los entrevistados refirieron frecuentemente una buena relación con directores y codirectores, a quienes se les reconocieron muchos aportes.

En consecuencia, los egresados de este recorrido fueron capaces de describir las singularidades y complejidades del proceso de tesis, mediante expresiones afectivas y metáforas significativas, tales como "relación amorosa", "tiempos de duelo y tiempos de concluir", "marea que sube y baja”, "es un parto", entre muchas otras. 


\section{Lo logró, pero lo sufrió}

En esta trayectoria se incluye a ocho egresados, quienes narraron un proceso en el que prevaleció el sufrimiento. Para ellos, adquirió mayor relevancia el costado doloroso de su experiencia sobre el matiz del aprendizaje. Si bien hubo egresados que pudieron "darse cuenta" de la necesidad de transformar algunas limitaciones, estos no lograron generar los cambios necesarios, es decir, "hacerse cargo".

Los entrevistados describieron el malestar que les deparó su recorrido particular. Así mismo, hablaron sobre el esfuerzo que supuso sobreponerse a distintos obstáculos aparecidos durante su trabajo de tesis. En algunos casos, varios de estos obstáculos estuvieron presentes en un periodo del proceso, y en otros, todo el tiempo.

Otro motivo desencadenante del sufrimiento se vinculó con sentirse presionados a hacer la tesis, sin la preparación suficiente. Concretamente, son los casos de los tesistas que no cursaron materias metodológicas.

Un factor adicional que generó preocupación en los tesistas fue la escasez o ineficacia de áreas de gestión de tesis, la falta de regulaciones del proceso, y la falta de formación en escritura académica. En este sentido, Julio manifestó:

La falta de apoyo. El no saber para dónde ir. Apoyo desde la facultad. Era arreglátela como puedas, hacela como puedas y chau. Obstáculos: la falta de acompañamiento, y que no teníamos una base sólida teórica, porque nosotros empezamos a estudiar con la creación de la Facultad, era todo un desastre, era luchar para que te den las cátedras, luchar para todo, no habia profesor porque habia paro o tenían que darte diez horas de matemática y te daban cinco. Nadie sabía por qué, era una falta de organización todo el tiempo. Andar girando de escuela en escuela, ese es un obstáculo acumulativo.

Una característica significativa de esta trayectoria grupal fue la percepción del tiempo como "demora" atribuida a los directores, 
evaluadores y a la institución. En ese sentido, los tesistas reflejaron estar "a la deriva", y con ello aludieron también a la falta de asesoramiento, de guía y de acompañamiento.

En relación con los directores, los egresados relataron desempeños diferentes. Para cuatro de ellos fue favorable, mientras que, para tres, desfavorable. Solo para uno fue indiferente, es decir, que no dejó ni aportes ni marcas negativas.

El de Pía fue un caso extremo de esta trayectoria de sufrimiento. Ella narró su experiencia como negativa y destacó que lo que aprendió fue a tenerle "terror a la tesis". Mencionó que en su proceso abundaron "las piedras en el camino" y que la tesis fue una "traba". Al respecto, informó:

Aprendi que le tengo terror a una tesis. Yo quiero estudiar posgrado y digo, ay, otra vez pasar por este proceso. [...] y a no bajar los brazos. Igual, yo soy de esas personas que si me planteo algo lo voy a cumplir. Sea lo que sea, lo voy a cumplir. Yo estaba muy decidida de que no podia haber hecho tanto esfuerzo y tantas ganas y que me encanta la carrera y todo. No lograrlo, yo lo iba a lograr, como sea, contra quien sea.

Su discurso apareció como un relato quijotesco para la obtención del título, como una lucha solitaria sostenida por su tesón personal y por el gusto por la carrera.

\section{Sobrevolando la tesis}

En esta trayectoria se incluye a cuatro entrevistados, quienes se posicionaron en un lugar diferente al de tesistas de licenciatura, por eso aparecieron como "sobrevolando" ese proceso.

Los egresados tenían formación anterior, títulos previos y práctica profesional, eso les otorgó más herramientas desde donde construir su proceso de tesis. Con respecto a esto, Mercedes expresó: 


\begin{abstract}
E: ¿Tuviste algún problema/s para la realización de la tesis? ¿Cuáles? ¿Cómo los resolviste?
\end{abstract}

M: Fui resolviendo a lo largo de la misma. Creo que me llevó mucho tiempo, que ahora, después de haber cursado la maestría en Salud Mental y haber realizado otro diseño de tesis con la guía de María Teresa Sirvent, me pareció innecesario tanto tiempo para la tesina mencionada.

Los casos incluidos en esta trayectoria grupal dieron cuenta de los obstáculos mencionados en las otras trayectorias, pero sus protagonistas les otorgaron un significado diferente. Su posicionamiento subjetivo fue distinto. Las experiencias relatadas hablaron acerca de la idea de la educación como transformadora de la persona y posibilitadora de un cambio cualitativo, con lo cual se comprende que sea otro el lugar desde donde investigaron, leyeron, pensaron y escribieron.

Finalmente, el director tuvo menor incidencia en la tesis, lo que guardó coherencia con el proceso de cada tesista, ya que ellos contaban con esas otras experiencias que los llevaron a realizar una trayectoria distinta.

\title{
Las metáforas: desencapsulando significados
}

Los entrevistados aportaron 26 objetos que fueron analizados como metáforas. Algunos criterios analíticos utilizados fueron: formato, densidad y temas.

Con relación al formato, 12 de los objetos metafóricos fueron imágenes -fotos, imágenes, pinturas-y 14 fueron palabras -poesías, canciones, frases, nombres-. Se ofrece un ejemplo de cada formato, seguidamente. 


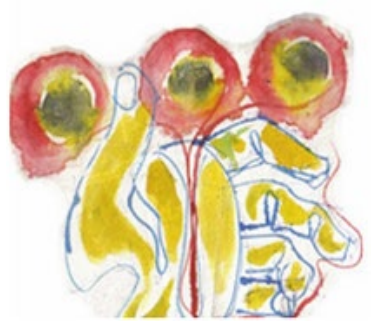

Figura 1.

Fuente: Constantino

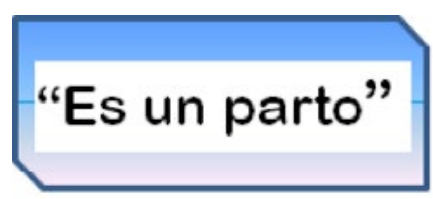

Figura 2. Alumbramiento Fuente: Julio

Por otro lado, el criterio de densidad se refiere a la presentación de una o más metáforas por parte de los entrevistados. En el siguiente ejemplo, Paloma aportó cuatro imágenes para representar su proceso de tesis. El título de cada una de ellas corresponde al nombre asignado por la egresada.

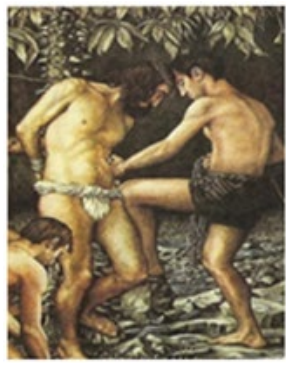

Figura 3. Tortura - Martirio Fuente: Paloma

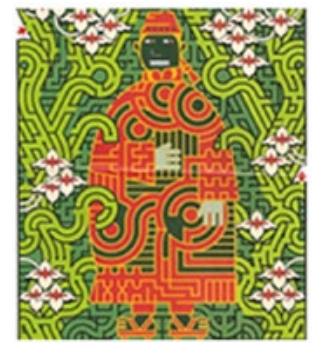

Figura 5. Laberinto Fuente: Paloma

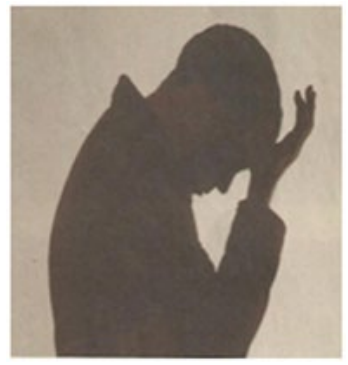

Figura 4. Preocupación Fuente: Paloma

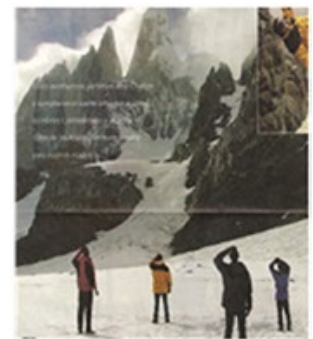

Figura 6. Desafio a recorrer Fuente: Paloma 
En este caso requirió poco esfuerzo comprender la estructura metafórica, marcada por la tonalidad de los sentimientos con los que Paloma transitó su proceso de tesis. Sin embargo, las imágenes implicaron un aporte en relación con los datos brindados en su entrevista, ya que discursivamente no mostró este aspecto "más sufrido" que sí apareció aquí. Esto pone de relieve que los discursos de los informantes suelen encapsular emociones y estados de ánimo.

El tercer criterio analítico estuvo relacionado con los temas a los que los objetos metafóricos refirieron. Dichos temas se organizaron en función de seis ejes. El primero de ellos se vinculó con la importancia de los otros, en tanto emergió la revalorización de personas teñidas de afecto, tales como: director, compañeros y familiares.

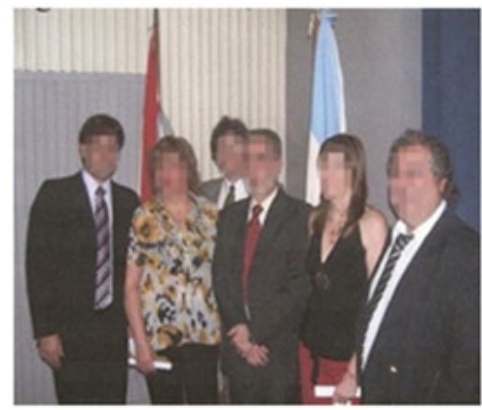

Figura 7. La tesis nunca se hace en soledad Fuente: Nicolás

El segundo tema relacionado con las metáforas fue el trabajo de campo; un momento de la investigación narrado como su "referente empírico, la porción de lo real que se desea conocer, el mundo natural y social en el cual se desenvuelven los grupos humanos que lo construyen" (Guber, 2004).

Las metáforas que lo representan muestran imágenes directamente vinculadas tanto a los sujetos participantes como al espacio geográfico donde fue llevado a cabo. Vanina complementa su imagen con la palabra "divertido", con lo que connota la tarea como una experiencia agradable, a la vez que señala las marcas positivas que esta instancia dejó en su vida. 


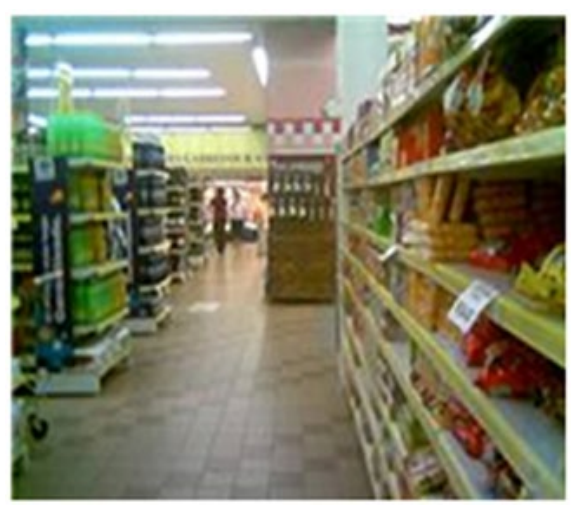

Figura 8. El escenario de la tesis Fuente: Vanina

El tercer tema fue el proceso de tesis, que incluyó la descripción de sus características y aludió a emociones positivas o negativas producidas en este recorrido. Dichas emociones generaron efectos humanos, así como cambios cognitivos que incidieron en los modos en que los tesistas transitaron y vivenciaron sus trayectorias.

Tal es el caso de Lidia, para quien la metáfora elegida fue una frase que la acompañó durante su tesis, que nos permitió inferir el valor emocional del proceso y el peso que enfrentó para lograr su egreso.

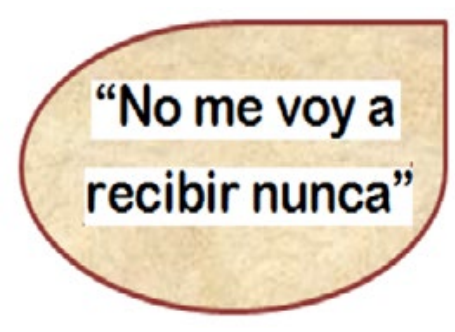

Figura 9. La profecía no cumplida Fuente: Lidia

El cuarto tema se relacionó con el cierre del proceso de tesis, es decir, con aquellas metáforas asociadas al momento de entrega del informe final o de la defensa, que remitieron a un cierre con diferentes matices. En el caso de Muriel, el final adquirió el sentido de "llegada a la meta", de 
logro, de haber alcanzado el objetivo educativo. La entrega del informe de la tesis o el momento de la defensa fueron mencionados por varios egresados como el fin del recorrido, como el cierre del proceso.

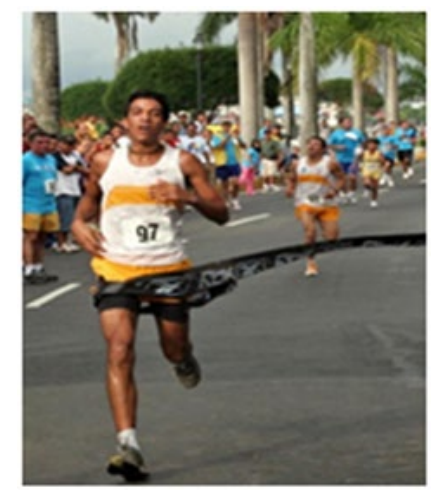

Figura 10. La llegada

Fuente: Muriel

El quinto tema asociado con las metáforas fue el aprendizaje como transformación. Este permitió identificar los aprendizajes vivenciados por los egresados, significados como transformadores. Aprender es un proceso que se desarrolla a lo largo de la vida y que produce transformaciones en todos los planos del ser humano. En el caso de Federico, la metáfora elegida remitió a varios términos en los que intenta resaltar la identidad entre ellos. Esta comparación permitió abordar cierta similitud entre conceptos aparentemente no relacionados que, al ligarlos, profundizan y amplian el panorama comprensivo, en este caso de la trasformación subjetiva producto de la realización de la tesis.

La marea. Sube y baja, es como estar enamorado. Y el duelo también, porque tiene como momentos de mucho dolory después como baja y sube, esto del duelo del estudiante perdido. Sentis que te transformas cuando terminas."

Figura 11. La transformación Fuente: Federico 
Finalmente, el sexto tema se vinculó con el proceso de formación, es decir, con aquellas metáforas que excedieron la tesis y sus momentos, y que ampliaron la referencia al proceso de formación en la universidad. En el caso de Lorena, el cuadro Le Thérapeute, de Magritte, es un objeto surrealista que invita a otra visión de las cosas, liberada de las reglas y de las enseñanzas recibidas, de las tradiciones, de la seguridad. Igualmente, este ofrece una mirada crítica acerca de la academia, pues la representa como una "jaula" que aprisiona la libertad del pensamiento y encierra la originalidad. Lorena criticó los modelos preestablecidos de "ser psicólogo", y expresó que al recibirse la jaula se abrió, permitiéndose devenir "pájaro". Completa su metáfora con la siguiente frase: "Solo queda esa imagen, una jaula disfrazada, sin nadie que la habite. Por suerte el pájaro está en otro lado".

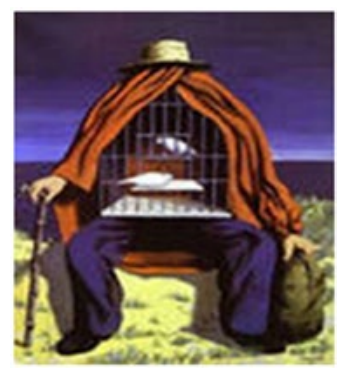

Figura 12. Le Thérapeute, de Magritte Fuente: Lorena

\section{Los procesos de tesis: un entramado discursivo y metafórico}

En función de lo anteriormente expuesto, podemos describir algunos hallazgos provenientes de la convergencia de las fuentes discursiva y metafórica.

Un primer hallazgo tiene que ver con que se construyeron cuatro trayectorias grupales y seis temas metafóricos, lo que nos permite inferir una mayor variabilidad de significado de lo metaforizado frente a lo relatado, en relación con momentos, sujetos y emociones. 
La solicitud de objetos - palabras, fotos, pinturas, imágenes-que representaran el proceso de tesis, permitió "objetivar", es decir, poner fuera de sí, un proceso que es interno, así como establecer una diferencia con el sujeto, que no anula la relación, sino que la expresa en su complejidad.

Es necesario darle un voto de confianza a la metáfora, perderle el miedo para tomarla como instrumento analítico de los fenómenos educativos. En una investigación rigurosa desconocer las metáforas implica perder un valioso campo de significación desde donde comprender a los sujetos que las emplean (Vázquez Recio, 2010).

Un segundo hallazgo se vincula a que las metáforas aportan un plus de sentido en relación con quienes fueron protagonistas claves en el proceso de tesis; las "marcas" dejadas por el trabajo de campo; el proceso de tesis que alcanzó a encapsular emociones; los cierres vivenciados; el aprendizaje logrado y vivido como transformación, y contextualizar la tesis en un proceso de formación académica.

Un tercer hallazgo permitió validar y profundizar las trayectorias grupales construidas. En nuestra investigación, el análisis de las metáforas muestra un alto grado de coherencia con el relato de los participantes. Dicho de otro modo, aparecen coincidencias o continuidades entre las expresiones discursivas y metafóricas por parte de los egresados, en especial, en relación con las "marcas" positivas o negativas que los diferentes momentos y protagonistas de los procesos les imprimieron. Es así como validan las construcciones analíticas generadas a partir de los datos obtenidos de las entrevistas en profundidad.

Por último, estas dos fuentes de información lograron complementarse y captar la complejidad de los procesos de tesis, dando cuenta del ensamble entre sus aspectos cognitivos y afectivos.

Como cierre, la metáfora captura el modo en que las personas interpretaron su proceso de tesis. Conocer los significados otorgados a ellos puede ser un indicador de las modificaciones que resultan 
necesarias, y la posible dirección que podría tomarse para modificar en alguna medida este aspecto de la formación de grado.

Las metáforas permiten a las personas interpretar una experiencia en función de otra que se comprende mejor, por lo que acceder a un mayor entendimiento sobre cómo los estudiantes viven sus procesos de tesis puede aportar nuevas ideas a través de las cuales se vayan mejorando las intervenciones que realizan los diferentes actores institucionales. En definitiva, se trata de que un día las tesis se asocien más con oportunidades de aprendizaje o mayor conocimiento que con tormentas, torturas, corsés teóricos o piedras en el camino.

\section{Referencias}

Banks, M. (2008/2010). Los datos visuales en la Investigación Cualitativa [C. Blanco Castellano y T. del Amo Martín, Trads.]. Madrid: Morata.

Bartolini, A., Vivas, D., Ferreira, C. y Petric, N. (2013). La trayectoria de los tesistas. Un estudio en egresados de la UADER. Informe de Investigación de Desarrollo Anual (PIDA), Universidad Autónoma de Entre Ríos.

Bonetto, M. J. (2014, septiembre). La fotografia como herramienta para la investigación social: una aproximación teórica. Actas del I Congreso de Investigación Cualitativa en Ciencias Sociales, Córdoba.

Carlino, P. (2003, agosto). ¿Por qué no se completan las tesis en los posgrados? Obstáculos percibidos por maestrandos en curso y magistri exitosos. Actas de las X Jornadas de Investigación en Psicología. Facultad de Psicología, Universidad de Buenos Aires.

Carlino, P. (2004). Diario de tesis y revisión entre pares: análisis de un ciclo de investigación acción en talleres de tesis de posgrado. Recuperado de: http:// www.escrituraylectura.com.ar/posgrado/articulos.htm

Carlino, P. (2008, septiembre). Desafios para hacer una tesis de posgrado y dispositivos institucionales que favorecerian su completamiento (Conferencia 
plenaria). Segundo Encuentro Nacional y Primero Internacional sobre Lectura y Escritura en la Educación Superior. Red Nacional para el Desarrollo de la Lectura y Escritura en la Educación Superior (Redlees), Asociación Colombiana de Universidades (ASCUN) y Universidad Javeriana, Bogotá.

Carlino, P. (2009). Exploración de géneros, diario de tesis y revisión entre pares: análisis de un ciclo de investigación-acción en talleres de tesis de posgrado. En E. Narvaja de Arnoux (Dir.), Escritura y producción de conocimiento en las carreras de posgrado (pp. 220-239). Buenos Aires: Santiago Arcos.

Civarolo, M., Aiello, E. y Pérez, M. (2013). La metáfora como rasgos de la infancia. En M. Civarolo, M. Fuentes y D. Villafañe (Comps.), Primer Congreso Internacional "La Infancia en Perspectiva. Múltiples miradas sobre las nuevas culturas del aprendizaje y el desarrollo en la infancia”. Universidad Nacional de Villa María, Villa María.

De Gracia, M. y Castelló, A. (2003). Metáforas y modelos en psicología cognitiva. Anuario de Psicología, 34(1), 29-52.

Denzin, N. K. y Lincoln, Y. S. (Comps.). (2011). El campo de la investigación cualitativa [C. Pavón, Trad.], Vol. I. Barcelona: Gedisa.

Gerstenblatt, P. (2013). Collage Portraits as a Method of Analysis in Qualitative Research. International Journal of Qualitative Methods, 12, 294-309.

Guber, R. (2004). El salvaje metropolitano. Buenos Aires: Paidós.

Harper, D. (2002). Talking about pictures: a case for photo elicitation. Visual Studies, 17(1), 13-26.

Lakoff, G. y Johnson, M. (1980/2001). Metáforas de la vida cotidiana [C. González Martín, Trad.]. Madrid: Cátedra.

Mendizábal, N. (2006). Los componentes del diseño flexible en la investigación cualitativa. En I. Vasilachis de Gialdino (Coord.), Estrategias de investigación cualitativa (pp. 65-105). Buenos Aires: Gedisa. 
Meo, A. y Dabenigno, V. (2011). Imágenes que revelan sentidos: ventajas y desventajas de la entrevista de foto-elucidación en un estudio sobre jóvenes y escuela media en la Ciudad de Buenos Aires. Metodología de Ciencias Sociales, $22,13-42$.

Narvaja de Arnoux, E., Borsinger, A., Carlino, P., Di Stefano, M., Pereira, C. y Silvestre, A. (2004). La intervención pedagógica en el proceso de escritura de tesis de posgrado. Instituto de Lingüistica, Universidad de Buenos Aires, Buenos Aires. Recuperado de: http:/ /www.escrituraylectura.com.ar/posgrado/ articulos.htm

Schwarz, P. (2014, septiembre). Consideraciones metodológicas sobre el análisis de fotografias publicadas en el espacio virtual. Actas del I Congreso de Investigación Cualitativa en Ciencias Sociales. Córdoba.

Scribano, A. (2008). El proceso de investigación social cualitativo. Buenos Aires: Prometeo.

Scribano, A. (2013). Encuentros Creativos Expresivos: una metodología para estudiar sensibilidades. Buenos Aires: Estudios Sociológicos Editora.

Strauss, A. L. y Corbin, J. (2002). Bases de la investigación cualitativa. Técnicas y procedimientos para desarrollar la teoria fundamentada. Medellin: Universidad de Antioquia.

Styles, I. and Radloff, A. (2000). Jabba the Hut: Research students' feelings about doing a thesis. En A. Herrmann and M. M. Kulski (Eds.), Flexible Futures in Tertiary Teaching. Proceedings of the 9th Annual Teaching Learning Forum, 2-4. Perth: Curtin University of Technology.

Tay-Lim, J. and Lim, S. (2013). Privileging Younger Chidren's Voices in Research: Use of Drawing and a Co-Construction Process. International Journal of qualitative Methods, 12, 65-83.

Vasilachis de Gialdino, I. (2006). Estrategias de investigación cualitativa. Buenos Aires: Gedisa. 
Vázquez Recio, R. (2010). Las metáforas: objeto e instrumento de estudio. Aportaciones a la investigación educativa [60 párrafos]. Forum: Qualitative Social Research, 11(1).

\section{Cómo citar este artículo}

Bartolini, A. M., Vivas, D. R., Ferreira, C. y Petric, N. (2017). Relatos y metáforas. Dos aproximaciones para comprender los procesos de tesis. Universitas Humanística, 83, 109-132. http://dx.doi.org/10.11144/Javeriana.uh83.rmac 